\title{
7 The rebirth of the hospital Heterotopia and medical tourism in Asia
}

\author{
Audrey Bochaton and \\ Bertrand Lefebvre
}

\section{Introduction}

'Hospital is the new destination' (Globe Health Tours 2006: n.p.), and 'A little sightseeing, a little face-lift' (Doheny 2006: n.p.) are some of the sensational newspaper headlines that illustrate that medical tourism has become an important component of the tourism industry in recent years. There is wide media coverage of its escalation and much of it reports medical tourism as a positive development for the countries involved. This chapter looks at its growth in Thailand and India, particularly how healthcare is promoted as a 'unique experience' and assesses the significance of the Asian traveler for its expansion and subsequent consequences on local populations. Connell (2006: 1093) in presenting medical tourism as a combination of 'sea, sun, sand and surgery' argues that it is the answer for patients from developed countries who have to deal with long waiting lists and high costs. This Westerncentric point of view does not tell us much about the Asian medical tourists' motives and expectations. In this chapter, we focus on the Asian experience of medical tourism.

We approach the topic by examining the hospital and its transformations. Medical tourism is definitely giving birth to new places of care, e.g., new international patient wards. Hospitals designed for foreign patients have been planned in India, Middle East and Southeast Asia. In fact, hospital architecture, design and organization are being rethought through this prism of medical tourism. These hospitals face a dilemma of trying to meet local healthcare needs as well as the expectations of a tourism industry standard. Hence we find it relevant to investigate the services such hospitals provide and precisely how the 'new' patients' demands are being met. Foucault's (1967) theoretical concept of heterotopia will be employed to analyze the 'distinctive experience' of healthcare proffered in medical tourism. The main actors of medical tourism always stress the 'unique' experience it can offer patients coming from abroad. Only positive elements are emphasized and the medical treatment offered is said to be near to perfection. The whole experience emulates 'a realized utopia'.

For this research, we conducted fieldwork mainly in Bangkok, Thailand, and had extensive interviews with five top managers and health professionals 
AOT_4_007.qxd 6/25/08 13:35 Page 98

\section{Audrey Bochaton and Bertrand Lefebvre}

from two corporate hospitals (Bangkok International Hospital (BIH) and Bumrungrad International) as well as officials from the health and tourism ministries in 2006 (see Bochaton and Lefebvre 2006). Thailand was selected as it is a pioneer in medical tourism in Asia and currently leads the way in terms of the number of foreign patients treated each year. In addition, we also draw limited information gathered from fieldwork in India which provides a good contrast as the country entered the medical tourism sector much later. In the main, our analysis will focus on the two biggest private hospitals in Bangkok - Bumrungrad International and BIH. We will discuss Indian hospitals (e.g., Apollo Hospital Delhi) to elucidate our discussions.

The chapter is divided into two sections. The first introduces medical tourism in the Thai-Indian contexts. The second section provides a presentation of the concept of heterotopia and an analysis of medical tourism through it.

\section{Of Asian origins: the true face of medical tourists in Asia}

If the links between healthcare and tourism are relatively new, the nexus between health and tourism is far older. In the past, some forms of tourism were already set out to, directly or indirectly, increase health and well-being. In India, the hill stations (e.g., Mussoorie, Shimla) that are now so popular among the Indian middle class, were settled from the middle of the nineteenth century by the British administration for medical reasons (Harrison 1999). In India, religious pilgrimages allow people an opportunity to be 'cured' of their ailments (Sébastia 2002). In Thailand, a tradition of spas and massages has existed for centuries. Today, massage schools are specifically created for the purpose of teaching traditional techniques to foreigners. Hill or coastal resorts remain popular with Thais e.g., Hua Hin, seeking rejuvenation.

As the link between healthcare and tourism becomes increasingly common, it is easy to forget that the expression 'medical tourism' is based on a contradiction which combines the notions of leisure and pleasure with those of disease, suffering and treatment. The union of these two words suggests that healthcare is now associated with ubiquitous consumerism. Some of the promoters of medical tourism have been uncomfortable with the expression 'medical tourism'. At its 2005 Health Summit, the Confederation of Indian Industry (CII), one of the most active promoters of medical tourism in India, proposed to replace the term with 'medical value travel'. In Thailand, the Thai Authority for Tourism (TAT) is marketing medical tourism more as the euphemistic 'wellness tourism' through spas, naturopathy and relaxation therapies rather than serious ailments.

As discussed by Connell (2006), it is difficult to assess the exact number of patients involved in medical tourism. Hospitals and national health authorities differentiate in their statistics, between national and foreign patients. But the 'foreign patient' category remains extremely vague and often overemphasizes the real extent of medical tourism. Figures from the Department of Export Promotion (2002) in Thailand show that in 2002, 60 percent 
AOT_4_007.qxd 6/25/08 13:35 Page 99

Heterotopia and medical tourism in Asia

99

of foreign patients were expatriates living in Thailand or neighboring countries; 10 percent were tourists falling ill during their holidays and 30 percent made the trip specifically for healthcare. In our opinion, expatriates and sick tourists cannot be considered medical tourists since their use of medical facilities is not directly related to travel. For the purposes of this chapter, we understand the term medical tourism to be the phenomenon involving patients traveling overseas especially for an operation or medical treatment - 'where tourism is deliberately linked to direct medical interventions' (Connell 2006: 1094) and medical screening. Similar problems in defining what a tourist is are not confined to medical tourism but occur in many other forms of niche tourism (Equipe MIT 2002). This is why all the figures presented should be used with caution.

Regardless of this problem, the number of foreign patients is on the rise in India and Thailand. In Thailand, the number of foreign patients has risen from 470,000 in 2001 (Pachanee and Wibulpolprasert 2006: 313) to an unexpected 1.4 million patients in 2006 (interview material). In India, it is believed that the number rose from 10,000 in 2000 to 175,000 in 2006 (interview material). Those figures could quite possibly be exaggerating the weight of medical tourism. As we have seen previously, such figures combine expatriates, tourists who fall sick during their vacation as well as those who come purely for the purpose of receiving medical treatment. The statistical system is weak and incomplete and some private hospitals are reluctant to divulge their figures. It is only now that public authorities have started to implement some tools to measure the phenomenon. In Thailand, before entering the country a traveler can specify whether or not they are coming for medical purposes. In 2005, India launched medical visas for foreign patients.

If we analyze in detail the figures in Table 7.1, we find that in 2004, more than 58 percent of the total number of foreign patients coming to Thailand were from Asia, including Australia. Japan was the top ranked country with almost 250,000 Japanese patients. At BIH, more than 90 percent of Japanese patients are expatriates working in the region. Between 2002 and 2004, Asian patients accounted for 80 percent of the total growth of foreign patients in Thailand. The growth between 2003 and 2004 was far more important for most Asian countries (ASEAN countries: +155 percent, Middle East: +105 percent, South Korea: +60 percent) compared to North American ( +39 percent on average) or European countries (+17.5 percent on average).

One of the important milestones in the story of medical tourism are events that took place on 11 September 2001 (collectively called the 9/11 attacks). Patients from the Middle East who used to travel to Europe (e.g., the UK) and the USA for medical treatment are now going to Thailand, India and other Asian countries. Visa constraints, coupled with a suspicious climate, have pushed them away from Western medical systems. BIH has seen the number of Emiratis increase by 318 percent from 2005 to 2006. In the Bumrungrad International Hospital, the number of Middle Eastern patients has multiplied 14 times between 2000 and 2005 to reach the 70,000 mark. This growth 
AOT_4_007.qxd 6/25/08 13:35 Page 100

100 Audrey Bochaton and Bertrand Lefebvre

Table 7.1 Foreign patients in Thailand (2002-2004)

\begin{tabular}{lrrrrr}
\hline \multirow{2}{*}{$\begin{array}{l}\text { Country/Region } \\
\text { of origin }\end{array}$} & \multicolumn{2}{c}{ Number of patients } & & \multicolumn{2}{c}{\begin{tabular}{l} 
Growth \\
$2003-2004$ \\
\cline { 2 - 4 }$(\%)$
\end{tabular}} \\
\cline { 2 - 4 } Japan & \multicolumn{1}{c}{2002} & \multicolumn{1}{c}{2003} & 2004 & $2004(\%)$ & 52 \\
South Asia & 131,584 & 162,909 & 247,238 & 22 & 55 \\
ASEAN & 47,555 & 69,574 & 107,627 & 10 & 155 \\
Middle East & - & 36,708 & 93,516 & 8 & 105 \\
Taiwan \& PRC & 20,004 & 34,704 & 71,051 & 6 & 22 \\
Australia & 16,438 & 46,624 & 57,051 & 5 & 45 \\
South Korea & 14,877 & 24,228 & 35,092 & 3 & 60 \\
Asia & $\mathbf{2 5 7 , 9 3 7}$ & $\mathbf{3 9 4 , 3 3 5}$ & $\mathbf{6 4 2 , 8 7 8}$ & $\mathbf{5 8}$ & $\mathbf{6 3}$ \\
Britain & 41,599 & 74,856 & 95,941 & 9 & 28 \\
Germany & 18,923 & 37,055 & 40,180 & 4 & 8 \\
France & 17,679 & 25,582 & 32,409 & 3 & 27 \\
Scandinavia & - & 19,851 & 20,990 & 2 & 6 \\
Europe & $\mathbf{7 8 , 2 0 1}$ & $\mathbf{1 5 7 , 3 4 4}$ & $\mathbf{1 8 9 , 5 2 0}$ & $\mathbf{1 7}$ & $\mathbf{2 0}$ \\
U.S.A. & 59,402 & 85,292 & 118,771 & 11 & 39 \\
Canada & - & 12,909 & 18,144 & 2 & 41 \\
North America & $\mathbf{5 9 , 4 0 2}$ & $\mathbf{9 8 , 2 0 1}$ & $\mathbf{1 3 6 , 9 1 5}$ & $\mathbf{1 2}$ & $\mathbf{3 9}$ \\
Others & $\mathbf{2 3 4 , 4 6 0}$ & $\mathbf{3 2 3 , 6 5 2}$ & $\mathbf{1 3 3 , 7 8 2}$ & $\mathbf{1 2}$ & $\mathbf{- 5 9}$ \\
TOTAL & $\mathbf{6 3 0 , 0 0 0}$ & $\mathbf{9 7 3 , 5 3 2}$ & $\mathbf{1 , 1 0 3 , 0 9 5}$ & $\mathbf{1 0 0}$ & $\mathbf{1 3}$ \\
\hline
\end{tabular}

Source: compiled from TAT 2005

is likely to accelerate in the future with the signing of numerous Memorandums of Understanding between the big private Thai hospitals and some public bodies (army, government departments) from the Middle East.

In India, it is difficult to obtain an equally detailed picture of medical tourism. Following interviews in Delhi, it appears that foreign patients come mainly from other South Asian countries (Bangladesh, Nepal, and Afghanistan). East Africa, the Middle East and increasingly Central Asia can be considered as secondary zones. The truth remains that the typical medical tourist in India is a non-resident Indian (NRI) living abroad (usually a developed country) who travels for medical treatment to his/her 'homeland' during his/her holidays. According to the Indian medical professionals we interviewed, NRIs come largely for health checks and plastic surgery. As such, it would not be presumptuous to say that Indian medical tourism has some elements of 'Asians on tour'.

Foreign patients now account for more than 40 percent of the patients in the Bumrungrad International and BIH in Bangkok. The increasing presence of medical tourists in these facilities, combined with the drive of private hospital groups to attract more medical tourists, creates a major makeover in the organization and the architecture of the hospitals, to which we now turn. 
AOT_4_007.qxd 6/25/08 13:35 Page 101

Heterotopia and medical tourism in Asia

101

\section{Medical tourism as a heterotopia}

\section{The concept of heterotopia}

In Of Other Spaces, Foucault (1967: n.p.) explains heterotopia:

First there are the utopias. Utopias are sites with no real place ... There are also, probably in every culture, in every civilization, real places ... which are something like counter-sites, a kind of effectively enacted utopia ... Places of this kind are outside of all places, even though it may be possible to indicate their location in reality. Because these places are absolutely different from all the sites that they reflect and speak about, I shall call them, by way of contrast to utopias, heterotopias.

Foucault presents six principles in order to qualify the heterotopias: heterotopias arise around points of crisis; their nature changes according to the era considered; they are capable of juxtaposing in a single real place several spaces; heterotopias function with unconventional time; they 'always presuppose a system of opening and closing that both isolates them and makes them penetrable'; finally, 'their role is to create a space that is other, another real space, as perfect, as meticulous, as well arranged as ours is messy, ill constructed, and jumbled'.

Some geographers have made interesting use of heterotopia to study gated communities (Hook and Vrdoljak 2002) and tourist practices (Shackley 2002; Bartling 2006). We employ the same concept because we noticed that hospitals involved in medical tourism insist on presenting themselves as very different compared to normal hospitals. They are special from the environment they present, the time taken to give treatment, the type of recovery options, and so forth.

\section{The perfect medical experience}

\section{Heterotopia of crisis}

According to Foucault, we find heterotopias in every society through two different categories. First, there are the heterotopias of crisis which are 'privileged or sacred or forbidden places, reserved for individuals who are, in relation to society and to the human environment in which they live, in a state of crisis: adolescents, menstruating women, pregnant women, the elderly, etc.' (Foucault 1967: n.p.). Then there is the heterotopia of deviation 'in which individuals whose behavior is deviant in relation to the required mean or norm are placed' (ibid.: n.p.).

Nowadays, medical tourism concerns all patients who are sick and cannot find a solution in their own country. These people are still in a crisis stage: a crisis linked to the disease and all the ensuing physical and mental suffering 
AOT_4_007.qxd 6/25/08 13:35 Page 102

\section{Audrey Bochaton and Bertrand Lefebvre}

plus a crisis linked to inappropriate healthcare systems in the country of origin - a crisis of the patient in relation to his society. The milestone in medical tourism came at some point in the mid-1990s. Some patients started to travel to Thailand, India, Singapore and other Asian countries because of long waiting lists in the British National Health Service, an increasing number of Americans without medical insurance, and the stress on health systems trying to cope with a shortage of care and an aging population such as in Japan and Taiwan. It is easy to understand that it is financially worthwhile for patients who are not covered by health insurance to go abroad even when airfares are included. While in 2004 open-heart surgery cost US\$30,000 in the USA, the price was US\$14,250 in Thailand and US\$5-7,000 in India (Bartling 2006). We find in medical tourism, an important characteristic of heterotopia: 'that in many ways it is a spatial answer to a social problem' (Hook and Vrdoljak 2002: 211). Medical tourism provides the solution to many a social crisis.

In the aftermath of the 1997 financial and economic crisis of Southeast Asia, Thai private hospitals saw the middle class fleeing from their infrastructures. The proportion of patients using the public infrastructure rose from 25.4 percent to 48.5 percent between 1996 and 2001, while the proportion using private hospitals and clinics decreased from 26.9 percent to 17.7 percent during the same period (Pachanee and Wibulpolprasert 2006: 312). As one manager from $\mathrm{BIH}$ explained to us, the hospital was forced to change its strategy. The hospitals argue that since Bangkok is an international tourist hub, it should attract foreign patients. The hospital first tried to encourage patients from the expatriate community in Bangkok and from the rest of the Southeast Asia region through targeted marketing campaigns and community-oriented schemes. Later expatriates from the rest of the region (Laos, Cambodia, Burma, Vietnam), who were looking for quality care, became the target of their marketing efforts. Eventually, the local and rich population of these countries also became the target. The Bumrungrad Hospital in Bangkok took a similar step at the same time. Similarly, in India, we can consider the sudden upsurge in medical tourism as a supply-driven phenomenon. Low health insurance coverage in the Indian population has been, along with other factors, one of the major constraints on the development of corporate hospitals. In 2002, the CII asked the audit agency McKinsey to prepare a report on the future of Indian healthcare (Healthcare in India: The Road Ahead). The report highlighted the role that medical tourism could play in ensuring comfortable profits to finance and to feed the development of private hospitals. Following this report, the phrase 'medical tourism' became a buzzword among corporate hospitals and later in government circles.

\section{Time control}

'The heterotopia begins to function at full capacity when men arrive at a sort of absolute break with their traditional time' (Foucault 1967: n.p.). 
AOT_4_007.qxd 6/25/08 13:35 Page 103

Heterotopia and medical tourism in Asia

Foucault demonstrates how the cemetery or the museum are highly heterotopic places by being a place of loss of life and quasi-eternity on one side, or by accumulating time with 'the will to enclose in one place all times, all epochs, all forms, all tastes ... in an immobile place' (ibid.: n.p.).

Medical treatment time is generally divided into different stages, with consultations, then treatment/operation and later the recovery spread over time. Medical tourism proposes to go beyond this notion of time and to accelerate it. No time is wasted during the experience abroad. Time is under control from the first appointment to the recovery period. Both BIH and Bumrungrad Hospital present well-designed websites to inform international patients, still thousands of miles away, of the specialities delivered. Patients can get information about specialists, medical staff training, languages spoken and thus make an appointment via email with the doctor who seems best suited to the specific patient health problem.

BIH has also developed a network of referral centers in many Asian countries. The patients can approach the hospital from a familiar and reassuring entry-point and first meet local doctors before traveling to Bangkok. Once first contact is made and an appointment arranged, the patient can book an international flight and be in the hospital within a few days. Then comes the first consultation and very quickly, if required, the operation. This is one of the main sources of pride in these hospitals: to be available and efficient in a short time for patients. Information technology (IT) is a key factor in providing foreign patients with easy access to the treatment Thai and Indian private hospitals can offer. Patient management within the hospital is increasingly IT-intensive, with medical records being stored in data servers. This plays a crucial role in time reduction.

The existence of package tours including flight tickets, medical treatment and recovery also helps the acceleration of time. Time is under control and the patient is in a cocoon throughout his/her stay. Medical tourism also gives the patient the ability to control the course of his/her medical experience and to regain freedom of choice. By establishing a rupture with the classic medical time, the experience of medical tourism is therefore a heterotopic one in the sense defined by Foucault.

\section{The standard of excellence}

The last trait of heterotopias is that they have a function in relation to all the space that remains... Their role is to create a space that is other, another real space, as perfect, as meticulous, as well arranged as ours is messy, ill constructed, and jumbled.

(Foucault 1967: n.p.)

Foucault calls this a heterotopia of compensation and medical tourism clearly includes this function in the sense that the main actors pose as the perfect 
AOT_4_007.qxd 6/25/08 13:35 Page 104

\section{Audrey Bochaton and Bertrand Lefebvre}

response to the dysfunction of the healthcare system in other countries. Though for Western medical tourists, time is of importance, the issue of quality care is also paramount.

Quality is a common key standard in both tourism and healthcare sectors. In the medical field, quality refers first to skilled and well-trained medical staff. Thai and Indian hospitals involved in medical tourism therefore recruit doctors who were trained in Europe, Japan and North America. In the Bumrungrad Hospital, most of the doctors are certified by an American medical board (e.g., American Board of Pediatrics). Quality of care also means getting the best medical equipment and ensuring medical and security standards are as high as possible. Both hospitals have invested a lot of money in medical electronic equipment which ensure the latest technologies are accessed. If this equipment is bought for diagnostic or treatment purposes, it is also used as a selling point in hospital brochures and marketing material. In order to get recognition for their efforts in providing quality and to sign profitable deals with insurance companies, growing numbers of Asian hospitals are rushing to get US Joint Commission International (JCI) accreditation. In 2002, the Bumrungrad Hospital became the first hospital in Asia to get accreditation. The medical excellence factor attracts obviously both Asian and Western patients, but for many Asian patients this issue really matters. Some rare therapies are available in developed countries but are far beyond their means. Bumrungrad and BIH bring these treatments to Asian patients at a more affordable price.

Quality in the medical tourism sector is also about how patients are welcomed and cared for during their stay in hospital. Bumrungrad stipulates that medical staff must be fluent in English. Translators are also on hand to help and/or accompany patients. From the concierge who can pander to almost any whim, to the design of the furniture or the van that will bring the patients from the airport to the hospital, everything is done to ensure the patients' time in the hospital is a truly exceptional experience. The chance to recover in a resort or a hospital near the beach transforms the patient's stay into a pleasant, near perfect experience. Relying on its large hospital network, the Bangkok Hospitals group offers its patients the opportunity to rehabilitate after surgery in one of its hospitals in Pattaya or in Phuket.

\section{Rejuvenating the hospital}

\section{The redefinition of the hospital}

The hospital traditionally carries a 'heavy' message to patients: suffering, death, treatment, hygiene, isolation. All these elements are present in hospital architecture and the atmosphere prevailing in them has helped carry negative perceptions of hospitals throughout history. In a modernist post-Second World War period, the hospital appeared as a functional space rather than a living space (Gillespie 2002). 
One of the strengths of Foucault's analytics of heterotopia is 'that a society, as its history unfolds, can make an existing heterotopia function in a very different fashion' (Foucault 1967: n.p.). In our case, through medical tourism, the function and the design of the place 'hospital' are completely renewed. Its functions have diversified and evolved; medical tourism has intensified in Indian and Thai hospitals the need to make patients feel comfortable. The patient is of course primarily at the hospital for his/her health but having made such a long trip, the hospital cannot afford to disappoint the patient: a lot of attention is given to patient well-being. Like any tourist, the patient is also consuming the space he/she is surrounded by. With this is in mind, private hospitals are inspired by five-star hotels (Figure 7.1). Even the expression 'five-star hospital' is often used by managers to describe their hospitals.

When you enter the BIH, a hostess greets you and guides you to the reception or the concierge. In the same building, the ground floor consists of a central lobby containing plants, bamboo and fountains which create a pleasant ambience. All the furniture - chairs, desks, sofas - are made from good-quality wood and the natural light coming through the windows creates a comfortable place. It is now common for the patient to have his/her own private room where he/she may accommodate some guests for the night.

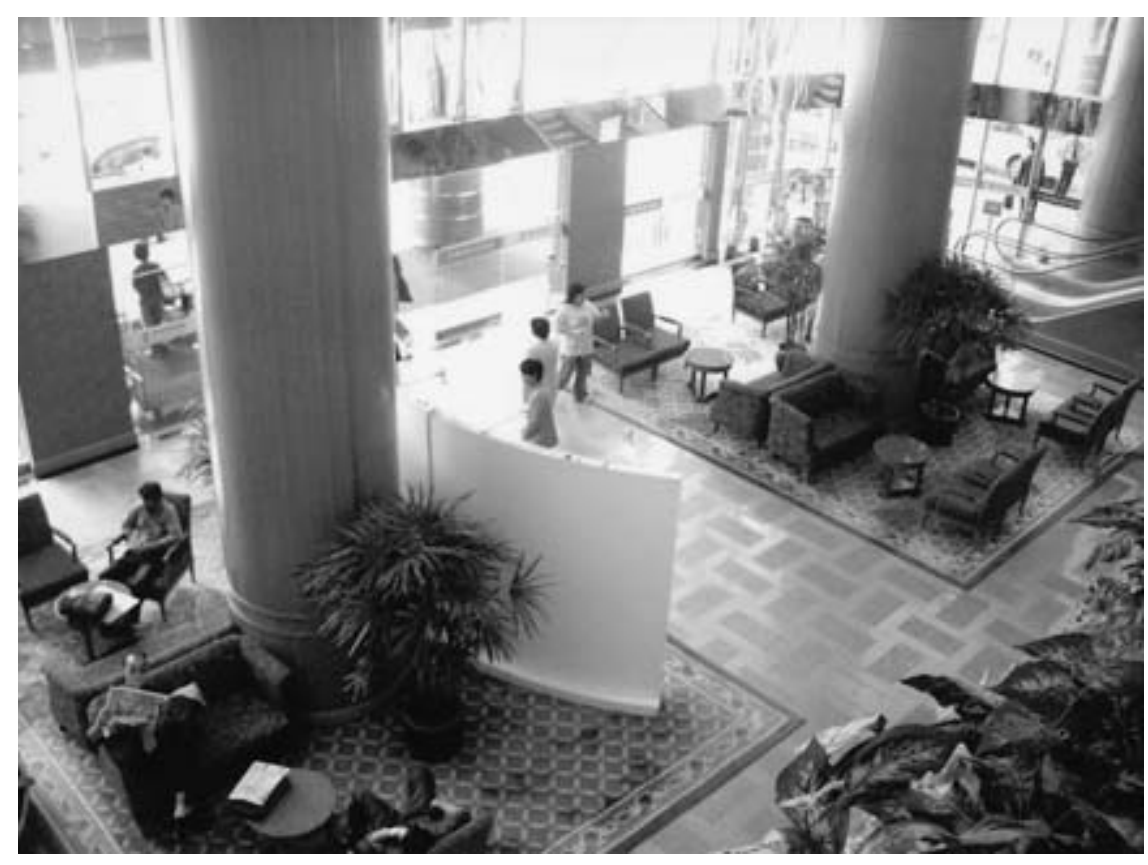

Figure 7.1 The main entrance of Bumrungrad Hospital is similar to any five-star hotel

\begin{abstract}
(Photo by authors)
\end{abstract}


AOT_4_007.qxd 6/25/08 13:35 Page 106

106 Audrey Bochaton and Bertrand Lefebvre

Some hospitals in India and Thailand are now even proposing suites with attached kitchen and living room. The reproduction of a hotel atmosphere in hospitals can be seen from the rooms' design and furniture. As explained on the Bangkok Hospital website (http://www.bangkokhospital.com/eng/ Room_Facilities.aspx), all rooms at Bangkok Hospital include the following: electrically adjustable beds, cable television including Thai, English and foreign language programs, a personal nurse call system, microwave oven, refrigerator, guest sofa-bed, telephone for local and international calls, individually controlled air conditioning, premium bathroom amenities and personal safe.

The food has also improved. In 2005, Bumrungrad International Hospital launched its Great Chefs Program and invited top chefs from leading hotels, and restaurants to cook dishes for its patients. Hospitals can no longer afford to offer foreign medical tourists, who are far from home, the same food they would offer local patients. Following this trend, Apollo Hospital in Delhi has adjusted its menus to suit the taste of its increasing number of foreign patients.

\section{Juxtaposition of realities}

One consequence of this reorientation is that the hospital is no longer just a hospital or medical place, but combines several realities. Foucault's criterion of 'juxtaposed realities' makes for useful application here. This criterion usefully draws attention to the ways in which the hospitals are a paradoxical balance of medical, consumerist and leisure space. As a headline from The Guardian emphasizes 'Is it a hotel? Is it a trendy bar? No, it's a hospital' (Purvis 2001: 14). This trend of diversification is also taking place in private hospitals globally: 'Late twentieth century hospital architecture has increasingly embraced the open space model of the shopping mall, housing commercial spaces such as shops, banks and restaurants which came to embody the power of commercialism' (Brandt and Stone 1999, cited in Gillespie 2002: 213). Medical tourism pushes this diversification logic to the limit'. The example of the Bumrungrad International Hospital is enlightening. We can find a huge food court similar to any found in shopping centers. There are now seven restaurants, ranging from McDonald's and Starbucks to Italian and Japanese restaurants. The Bumrungrad International Hospital has also a small supermarket, hair salon, flower shop, bookshop and two medical suppliers. Within the medical ward itself, there is now an immigration service desk where patients can renew their visas.

\section{New forms of segregation}

Finally, Foucault's last criterion of heterotopia is the idea of a strict and characteristic system of admission. 'Heterotopias always presuppose a system of opening and closing that both isolates them and makes them penetrable' 
AOT_4_007.qxd 6/25/08 13:35 Page 107

Heterotopia and medical tourism in Asia

107

(Foucault 1967: n.p.). Historically, the hospital perfectly adheres to this definition. We find necessary segregation according to the different types of care required or the contagiousness of diseases. The gatekeepers at the reception desks simultaneously ensure access to patients while also acting as a barrier to protect this 'closed' world. 'Everyone can enter into these heterotopic sites, but in fact that is only an illusion - we think we enter where we are, by the very fact that we enter, excluded' (ibid.: n.p.).

With medical tourism, the rules of segregation are changing and the spatial organization within the hospital is also undergoing a transformation. While many Indian hospitals continue accommodating the medical tourists along with local patients, in Thailand, some hospitals have adapted their infrastructure to this new foreign population. On the Bangkok Hospital campus, the BIH is dedicated exclusively to international patients. Thai patients have no reason to go to the international building or consult doctors working there because they have a building dedicated to local healthcare. Medical tourism thus creates in this case a space integrated in the classic medical fabric but functioning as a closed world. It is interesting to note here that the international building of BIH features internal divisions of space: indeed, three types of wards can be found: an 'Arab ward' for Middle Eastern patients, a 'Japanese ward' and 'a global international ward' for the other nationalities. Each ward is different from the others in the interior design, spatial arrangements, food services, prayer rooms, translator services and so forth. Such segregation is also the answer to some complaints about the experience of sharing the premises with patients from another nationality. This process creates a closer proximity for each type of patient according to their culture, religion and language but at the same time it creates a compartmentalized space and a model of segregation. Interestingly, the Bumrungrad International Hospital prefers to treat all patients equally, regardless of where they have come from.

\section{Conclusion}

Most of the time, a heterotopia is an 'other space' integrated within the social space when deviant behavior or a crisis appears. However one singularity of medical tourism lies in the fact that this heterotopia functions at an international scale. The 'crisis' (dysfunction of the healthcare system) takes place at some Western or Asian countries and medical tourism as a response (as a possible answer to this crisis from the point of view of the patients) occurs in another part of the world. In this sense, there is a spatial move from the origin of the problem to the location where it is resolved. In this context, the issues of impacts are important to consider insomuch as they act at two scales: on the national healthcare system of 'host countries' and more globally on the conceptions of health and healthcare linked to globalization.

It may be too early to judge whether medical tourism is having a positive or negative impact on local health systems. We can be sceptical when looking at the future. If medical tourism helps in part to reverse the brain drain in the 
AOT_4_007.qxd 6/25/08 13:35 Page 108

\section{Audrey Bochaton and Bertrand Lefebvre}

medical profession, with for example, many NRI doctors returning to India, it is also possible that medical tourism could exacerbate the brain drain between the public and private sector. The salary, better working conditions and the possibility of continuous training offered by the private hospitals are understandably appealing and are leading to a concentration of medical excellence in a small group of private hospitals. In order to minimize criticism, and to reassess their local roots, hospitals are involved in many charitable and community-oriented schemes, ranging from free health camps, to health awareness campaigns or the sponsorship of non-governmental organizations or social activities. Some hospital insiders explained to us that these efforts were largely cosmetic, designed to minimize criticism. Charitable activity helps to legitimate hospital activity and thus medical tourism in the host country.

Heterotopia is a valuable concept with which to study and follow the various transformations hospitals undergo when faced with the pressures of medical tourism. Nonetheless, conclusions about the impacts on medical tourism brought about by Asians on tour remain uncertain. Medical tourism's first asset remains the quality of care, a realm where you have to standardize medical procedures for safety reasons. Therefore, all the patients are equally treated. As many doctors in Thailand and in India kept telling us, they first face patients who are suffering. The nationality, the religion or the gender of the patients are secondary considerations to them. If the Asian medical tourists make an impact in terms of number compared to Western ones, the surveyed hospitals seemed to have largely ignored such categorizations in their functioning. Bumrungrad Hospital still mixes local and foreign patients. Hospitals are keen on offering tailor-made non-medical services to their patients. The creation of specific wards for foreigners in BIH was not based on an Asian/non-Asian distinction but on market sensitivity to the Japanese and the Middle Eastern patients who form the majority of foreign patients in this hospital. Following this trend, the next step for the biggest players of this market is to settle a network of hospitals in different parts of Asia in order to increase their patient pool. Bumrungrad International Hospital is soon due to open in 2008 one new hospital - with partly Thai staff and using Thai traditional architecture pastiche - in the Middle East. The objective seems not to make Arab patients to feel at home, but instead to recreate in Dubai the exotic atmosphere of a Thai hospital. If there is no Asian medical tourist, per se, medical tourism is accelerating the formation of an Asian hospital care market and pan-Asian hospital chains.

\section{Acknowledgements}

We would like to thank Professor Bernard Elissalde, Dr. Vincent Coëffé, Professor Peggy Teo, Dr. Tim Winter, Dr. Shalini Punjabi, Rajeshree Sisodia and Lorraine Bramwell for their input and reviews at various stages. 